\title{
PENÍNSULA CUMPLE DIEZ AÑOS
}

\author{
Daniela Maldonado Cano \\ coeditora de 2007 a 2012 \\ CEPHCIS, UNAM
}

\begin{abstract}
Durante esta primera década ha reunido en sus páginas el trabajo de especialistas consolidados y estudiantes de posgrado de una importante variedad de disciplinas que incluyen a lingüistas, historiadores, literatos, antropólogos, etnólogos, etnoecólogos, arqueólogos, filósofos y sociólogos, entre otros.

Acunada en el seno de la entonces Unidad Académica de Ciencias Sociales y Humanidades (UACshum), de la Coordinación de Humanidades de la Universidad Nacional Autónoma de México (unam), Península vio la luz en 2005, con el número 0 del volumen I, y un primer propósito: dar a conocer el trabajo de los académicos de la Unidad, en una publicación "atractiva, puntual y pertinente" y que además pudiera incorporar colaboraciones de diversos especialistas de y sobre la región.
\end{abstract}

A lo largo de estos diez años la revista ha tenido como editores a Mario Humberto Ruz Sosa — con quien colaboré primero como correctora y posteriormente como coeditora-, Ricardo López Santillán y Rubén Torres Martínez, actualmente a cargo, cuyos aportes han venido a delinear el carácter de la publicación en sus distintas épocas. Algunos números han contado también con la colaboración de editores invitados, versados en las temáticas en torno a las cuales se han conformado, a manera de dossier.

Abrir brecha, darse a conocer, integrar un listado de dictaminadores no sólo capaces, sino dispuestos a colaborar rigurosa y generosamente con una revista en ciernes, no ha sido fácil. Tampoco lo fue consolidar su propuesta: un espacio plural que diera cabida a trabajos académicos de calidad, provenientes de disciplinas afines a las Ciencias Sociales y las Humanidades.

Desarrollar una revista académica con este perfil en un ámbito en el que se tiende cada vez más a la especialización no ha sido fácil. Desde el planteamiento y la revisión constante de las normas editoriales, la dificultad que entraña lograr un cierto nivel de homogeneidad en escritos de tan diversa naturaleza ha sido un reto. La aproximación las fuentes, el manejo de las referencias y tecnicismos y el uso de claves y códigos, tablas, gráficos y fórmulas, y es distinto y particular en cada disci- 
plina. Así, el intento de armonizar esas visiones y responder a sus necesidades nos ha exigido a quienes participamos en el trabajo editorial de Peninsula la reflexión constante y la revisión profunda de la propuesta.

En el camino aprendimos la delicada tarea de revisar, evaluar, diseñar y definir el perfil plural y académico de Peninsula, nutriéndonos de la experiencia de otras importantes publicaciones periódicas de la UnAm y otras instituciones. Desde sus inicios, se asumió el compromiso de difundir el conocimiento surgido del quehacer científico y humanista. Pero la academia — y con ella, la propia Peninsula — no es la misma que hace una década y la difusión de sus productos debe hacerse acorde a los nuevos tiempos. Ahora nos encontramos con el reto de mantener el crecimiento y la difusión de nuestra revista, afrontando las exigencias de los lectores y los cambios y ajustes de las políticas editoriales, acorde con los nuevos recursos y herramientas tecnológicos. Entramos a la siguiente etapa de la revista, que sigue siendo joven, pero debe encaminarse a la madurez.

Indexada en scielo, Latindex y Clase y disponible en línea en el Portal de Revistas Científicas y Arbitradas de la UNaM, Península mantiene una convocatoria abierta para recibir contribuciones especializadas ya sea en artículos originales e inéditos o bien en forma de reseńas críticas sobre publicaciones vinculadas con las Ciencias Sociales y las Humanidades. El esfuerzo colectivo de quienes hemos participado en esta historia se refleja ahora en una revista que tiene su propia presencia y un perfil consistente y cada vez más reconocido.

Así, durante estos primeros años se establecieron las bases de lo que, espero, se afiance como un espacio respetuoso, plural, riguroso y diverso, que mantenga el respaldo de destacados académicos en su Consejo Editorial, que en una década ha reunido a más de una veintena de especialistas provenientes de diversas disciplinas y países, a quienes hemos de agradecer su apoyo.

Peninsula cumple diez años. Y los cumple gracias a la confianza de los autores quienes han contribuido con sus trabajos en cada uno de los números publicados; gracias a los dictaminadores, especialistas que han brindado su tiempo y atención para la revisión seria e imparcial de los textos propuestos; gracias a los académicos y el equipo de Publicaciones del CEPHCIs, presentes en cada volumen editado; gracias a los editores y, sobre todo, gracias al apoyo de la Universidad y sus autoridades y al interés de nuestros lectores. 